\title{
GCU
}

Glasgow Caledonian

University

University for the Common Good

\section{The role of the specially trained officer in rape and sexual offence cases}

McMillan, Lesley

Published in:

Policing and Society

DOI:

10.1080/10439463.2014.912648

Publication date:

2015

Document Version

Author accepted manuscript

Link to publication in ResearchOnline

Citation for published version (Harvard):

McMillan, L 2015, 'The role of the specially trained officer in rape and sexual offence cases', Policing and Society, vol. 25, no. 6, pp. 622-640. https://doi.org/10.1080/10439463.2014.912648

\section{General rights}

Copyright and moral rights for the publications made accessible in the public portal are retained by the authors and/or other copyright owners and it is a condition of accessing publications that users recognise and abide by the legal requirements associated with these rights.

Take down policy

If you believe that this document breaches copyright please view our takedown policy at https://edshare.gcu.ac.uk/id/eprint/5179 for details of how to contact us. 
The Role of the Specially Trained Officer (STO) in Rape and Sexual Offence Cases

\author{
Professor Lesley McMillan \\ Glasgow Caledonian University \\ Cowcaddens Road \\ Glasgow \\ G4 OBA \\ Lesley.McMillan@gcu.ac.uk
}

\begin{abstract}
The specially trained officer in rape and sexual offence cases performs a vital role in terms of case processing, supporting investigation and providing services directly to the victim of rape. Despite being regarded as a vital part of the post-assault processing of rape cases, specially trained officers have received scant attention in the research literature. This paper outlines the experience and importance of specially trained officers in one English county, and highlights that despite the importance of their role, officers are often poorly supported in the management structure. Individual officers recognise the importance of their role both in terms of victim support, and investigation, but report that immediate supervisors do not always share this view, leading to tensions in the process. The findings also indicate the particularly time-consuming nature of ongoing communication with the victim in cases of rape, but the incredible importance of this communication. It is argued that specially trained officers working in tandem with independent sexual violence advisors would alleviate the burden for specially trained officers, and improve communication with the victim, ultimately contributing to a more procedurally just outcome.
\end{abstract}

\title{
Keywords
}

rape; sexual offences; police; specially trained officer (STO); police culture

\section{Acknowledgements}

This research was funded by the Economic and Social Research Council (ESRC) Grant RES-061-230138-A. Research assistance from Michelle Thomas.

\section{Background}

The problem of a high attrition rate and a poor experience for the victim in rape cases has been the subject of much academic and policy discussion in recent decades. Despite an increase in reporting rates for rape the conviction rate has continued to decline (Kelly et al, 2005). Research also reveals that the majority of cases are lost at the earliest stages of the justice process - that is policing (Chambers and Millar, 1983; Gregory and Lees, 1997; Kelly et al, 2005; Temkin 2002) and that whilst the experience of the victim has improved somewhat (Adler, 1991; Frazier \& Haney, 1996; Lees \& Gregory, 1993; Temkin, 1997), many still report negative experiences of elements of the process (Jamel et al, 2008; Lea et al, 2003; Myhill \& Allen, 2002; Temkin, 1997, 1999, 2002). A number of interventions have been made throughout the justice process to improve both conviction rates and victim experience. One of these interventions at the policing stage of the criminal justice process was the introduction of chaperones in the early 1990s and subsequently Specially Trained Officers (STOs) a decade later (Stern, 2010). This role has been known variously in different forces by titles 
including STOs, Sexual Offence Liaison Offiers (SOLOs) and Sexual Offences Investigative Technique Officers (SOITs) among others.

STOs are regarded as a vital part of the investigation team (HMCPSI \& HMIP, 2007) but despite the importance of the role of the STO in rape and sexual assault cases, the topic has received remarkably little attention in policing, criminal justice, and criminological literature. Indeed, the roles of Specially Trained Officers and liaison officers more generally (including Family Liaison Officers) seem to be largely under-researched and receive little commentary other than a few articles in Police Review (see Curtis, 1995; Harrison, 1998; Nicholls, 1998; Hepworth, 2003; Morgan, 2003) and some brief coverage in other academic material (Jamel et al, 2008; Temkin, 1998). The few exceptions to this is Jamel et al's (2008) recent research in relation to male rape survivors and Temkin's (1999) research into the older chaperone role, both of which are discussed below. In order to address this knowledge gap, this paper explores the role of the STO in rape and sexual offence cases from the perspective of the officers who perform this role and those who work directly on rape and sexual offence reports.

\section{Victim Experience of the Criminal Justice Process}

Secondary victimisation in the justice process has been reported by a number of victims of crime (Shapland et al, 1985; Symonds, 1980; Resick, 1987) and is particularly an issue in the reporting of rape where secondary victimisation is a significant issue (Maier, 2008). The police are effectively 'gatekeepers' to the later stages of the criminal justice system (Frazier \& Haney, 1996; Seneviratne, 2004) and sympathetic handling of cases at the policing stage is very important as a negative experience is likely to influence victim withdrawal (Jordan, 2001; Kelly et al, 2005; Temkin, 1997, 1999). Indeed, many victims choose not to participate in the process (Frazier \& Haney, 1996) and research tells us that the policing stage is the most significant attrition point in reported rape cases (Chambers and Millar, 1983; Gregory and Lees, 1997; Kelly et al, 2005; Temkin 2002). Research also reveals that victims find recounting their rape or sexual victimisation very difficult and require sympathetic listeners to hear their story (McMillan and Thomas, 2009). Thus, it is clear that a 'positive' experience for the victim at the policing stage is of vital importance not only from the victim's perspective in terms of 'honouring the experience' and feeling heard (Stern, 2010) but also from an investigative and prosecution perspective. Successful prosecution of rape requires victims who are willing to participate in the process. As a result, and as The Stern Report notes, 'It is critical that the victim's first encounter with officialdom is sympathetic and professional.' (2010: 63). Not least because the way victims are treated by the police will impact on the quality of information provided (Jamel et al, 2008) and this will, in turn, impact on the quality of the investigation and any subsequent prosecution (Lonsway, Welch \& Fitzgerald, 2001).

\section{Police Role in Rape \& Sexual Offence Investigation and Prosecution}

The police are the first port of call for victims of rape who choose to engage with the criminal justice process and report the offence committed against them. It is the primary responsibility of the police to investigate allegations of rape and to provide the required evidence to the Crown Prosecution Service who will make decisions whether to charge'. As such, the police not only make an initial decision about whether a crime has taken place but also subsequently how to classify it (Frazier \& Haney, 1996). As such, eliciting the best quality evidence from the victim at initial report, and subsequent interview, is of vital importance and failure to do so can significantly impact on charging and prosecution decisions (McMillan and Thomas, 2009). A key aspect of the policing response to rape and sexual offences is the STO. The STO takes a key role in rape and sexual offences cases and is the primary point of contact for the victim throughout the process, irrespective of how far a case progresses. 


\section{The Specially Trained Officer}

This paper looks at the role of the STO in rape cases. It is important to contextualise the development of this role. Over time, the role of supporting the victim of rape through the police and criminal justice process has been performed by a number of specialists. In the early 1990s, in response to rising concern about the treatment of rape victims in the criminal justice process, the role of chaperone was introduced. Their role had a smaller remit than the current STO role, and did not attract the same training. The role of the chaperone was to support the victim throughout the case, refer the victim to relevant external and support agencies (including supporting Criminal Injuries Compensation claims) and to liaise between the investigating officer and the victim. The chaperone was not meant to be involved in taking first account statements from the victim. Temkin (1999: 19) cites the Metropolitan Police Service's Policy Guidelines that state chaperones should '... ensure that victims are treated with kindness, sensitivity and courtesy and to obtain the best possible evidence to aid an investigation and support any subsequent prosecution.' When performed well the chaperone scheme was a great success but there was a lack of consistency. In many cases procedures were not followed, certain individuals were over-deployed, supervision was poor, there was a lack of resources to do the job, and burn-out was likely (Sturman (2000), cited in Kelly, 2002). In her research with the Metropolitan Police Service in the 1990s, Temkin found that chaperones 'emerge as secondary victims in the rape process. Trained to be the standard bearers of the new regime, they find that in practice they are deprived of the time and resources to provide a proper service' (1999: 28).

The chaperone role was replaced in 2002 by another, more detailed, specialist role. This role had a number of different titles across police forces including SOLOs (Sexual Offence Liaison Officers), SOITs (Sexual Offence Investigative Technique), RTOs (Rape Trained Officers) and VLOs (Victim Liaison Officers). This role was subsequently re-named and given a standard term Specially Trained Officer (STO) following publication of the report by HMCPSI and HMIC report in 2007. The title SOLO has been retained by the Police force in this research.

STOs have a number of responsibilities that include: responding to an initial report of a sexual offence; arranging and supporting the forensic medial examination including briefing the forensic practitioner and securing samples taken from the victim; briefing the investigating officer and crime scene investigator and manager; conducting the victim interview ${ }^{\text {ii; }}$ liaising with the victim in relation to case progress; and taking statements of withdrawal of support for the prosecution (HMCPSI \& HMIP, 2007).

With one or two exceptions, the STO role has received relatively little attention. A joint review of the prosecution of rape cases conducted by HM Crown Prosecution Service Inspectorate and HM Inspectorate of Constabulary (2007) revealed that whilst the formal introduction of the STO had greatly improved the initial response to rape, a number of difficulties relating to the deployment, supervision and management remained. Specifically, these related to the poor management of rotas and call-out lists, deploying officers based on who was most readily available without reference to that officer's existing commitments (as an STO or otherwise) or core workload. The report also stated that officers with experience of having performed the role well would be repeatedly called upon potentially leading to over-deployment.

The report also draws attention to the consequences of poor management of STO deployment in terms of poor morale and efficiency as a result of the multiple demands being placed upon them as both STOs and response police officers. The lack of a shared understanding of the STO role at supervisory level meant STOs were subject to pressure form line managers to return to their 
response policing role resulting in officers being torn between their dual roles. However, the report highlights that despite these problems, the services provided by officers was a good one. As a result of these findings, the HMCPSI and HMIC report made the following recommendation: ' ...there is a need for forces to review call-out lists and rotas, formally monitor STO deployment and review supervisory structures to ensure that line management responsibility for STOs following deployment and during investigations is clearly defined.' (2007: 11).

The role of an STO is a meant to be self-selecting, and therefore voluntary, however the HMCPSI \& HMIC (2007) report found that in some force areas a paucity of STOs meant some officers felt pressured to agree to train for the role. The report also noted that any assessment of the suitability of officers for the STO role was a very rare occurrence with the exception of the Metropolitan Police Services' specialist Sapphire Unit. All the forces involved in the HMCPSI \& HMIC (2007) report indicated the challenges surrounding officers being trained to do the STO role, but either failing to, or not having the chance to, engage once training was complete. As a result trained officers are then deskilled or remove themselves from the STO role. The review also found little evidence that performance monitoring of STOs took place, and nor was feedback from Investigating Officers to STOs a common occurrence.

Jamel et al (2008) investigated the role of the STO in the Metropolitan Police Service. Using a questionnaire-based approach, they explored their roles and responsibilities, the practical issues they face, their investigative function, what barriers there were to effective performance and what elements of good practice could be identified. They found a number of issues relating to the STO role. Firstly, victims were not always allocated one STO for the duration of their case. Often, due to a lack of resources and availability, victims had more than one STO, thus leading to a lack of continuity. They also found that the limited resources available to STOs impacted on their ability to do the job as effectively as they might. Additionally, they highlighted the issue of on-going communication with the victim. They found that this was variable among officers and dependent upon an officers' perception of the victim's needs as well as the time available to the STO to conduct this aspect of the role - these two aspects may, of course, not be compatible. This provides further evidence that the STO role has some challenges, not least to do with deployment, time and resource allocation, and suggests a variable experience for the victim of rape.

The available research conducted to date highlights that, if performed well, the role of the STO is of vital importance not only to the ultimate criminal justice outcome in terms of facilitating an adequate investigation and prosecution and for keeping the victim engaged with the process, but also for ensuring a greater level of victim satisfaction in terms of ongoing communication and sympathetic and sensitive treatment of victims.

\section{Procedural Justice}

As we have seen, victim experience matters in, and of, itself, but also because a negative experience for the victim significantly impacts upon the likelihood of victim withdrawal, acknowledged as a major part of the attrition problem at the policing stage (see above). The conviction rate for rape is so low that victims are not guaranteed a positive outcome in terms of criminal justice. There are however a number of ways of measuring a 'just' outcome, and the concept of procedural justice is a useful one here.

'Procedural justice refers to the judged fairness of procedures.' (Wemmers et al, 1995: 329). The concept was first developed by Thibaut and Walker in 1975. They studied civil disputes and found more satisfaction among individuals when they felt involved in the process, rather than excluded and denied information. A similar phenomenon has been found amongst victims of crime. Those 
who feel they were treated fairly by criminal justice authorities and institutions are generally more satisfied (Erez \& Bienlowska, 1993). As Wemmers et al argue, 'What victims want from legal authorities is to be treated with respect'. (1995: 332) and shown interest and understanding (Shapland et al, 1985). The research evidence highlighted above certainly indicates that this is the case for victims of rape and sexual offences - crimes that fundamentally challenge a victim's sense of dignity and autonomy - and when victims are not treated appropriately secondary victimisation occurs.

A sense of procedural justice and fairness is important when people are reacting to personal encounters with the police (Tyler, 1990). Procedural justice can be seen as procedural fairness, or put differently, treating victims fairly and with dignity and respect. It is also likely that victims will be more cooperative with the police if they feel they are treated fairly, an issue of relevance in rape cases given the high rates of victim withdrawal. People are likely to feel more valued if in their interactions with legal institutions like the police they are allowed to have their say (or tell their story) believe they are taken seriously, and that they or their complaint is not prejudged (Paternoster et al, 1997). All of these issues are of vital importance in cases of rape. Lind \& Tyler (1988) argue that judgements about procedural justice are based upon three factors: standing people want to be treated with dignity and respect because it enhances feelings of self-worth; neutrality - an absence of bias and decisions made on the basis of information and fair procedures; and lastly trust - a concern for the needs of the individual and an intention to act fairly. They also argue that judgements about procedural justice are normative and not instrumental. Therefore, victims are concerned about their treatment in the process rather than influencing the outcome of their case.

We know that 'outcomes are not the only thing people care about. They are also concerned about how a particular outcome or decision was reached. Negative outcomes are far more agreeable when they are reached following fair procedures.' (Wemmers et al, 1995: 300). It should however be noted that the argument here is not that conviction rates do not matter - they are of vital importance and must be improved in relation to rape - it is that the rape reporting and prosecution process needs to be viewed holistically and a number of types of justice taken into account. The STO role, then, could and arguably should, be seen as an integral part of procedural justice.

This paper explores the role of the STO from the perspective of the police officers who perform it, and from the perspective of officers who regularly investigate complaints of rape. It explores the issues affecting officers and impacting on the successful performance of the STO role, and the extent to which this contributes to procedural justice for victims of rape - arguably as equally important a 'measure' of how the criminal justice system response to rape and sexual offences as the prevailing conviction rate.

\section{Methods}

Police interview data was collected as part of a larger study which aimed to explore factors influencing attrition in rape cases. The study took a case study approach and as such all data for the study was collected in one English country. The police fully supported the study and for the purposes of the research, generated a list of all police officers in the force who had dealt with at least one rape in the last 12 months, either as an 'Officer in the Case' (OIC) investigating officer, or as a an

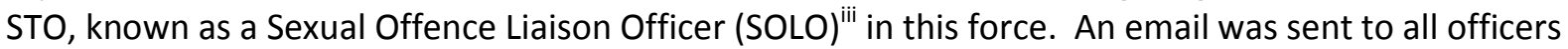
on this list from the Superintendent, Head of Specialist Investigations Branch, CID, explaining about the study, and alerting them to the fact they may be contacted by a researcher and invited to take part in an interview. We drew a purposive sample from this list to cover geographical policing divisions in the force area and gender. These officers were then contacted by email. A total of 35 
SOLO officers and 11 investigating officers were contacted of whom, 11 SOLOs and 9 investigators agreed to take part in a semi structured interview ${ }^{\text {iv }}$. A further 13 officers emailed and volunteered to be interviewed after receiving the email from the Superintendent. A further seven senior officers ${ }^{v}$ (Detective Chief Inspectors and above) were also interviewed. This resulted in a total of 40 interviews, consisting of 7 female and 6 male SOLO officers, and 7 female and 20 male detectives ${ }^{\mathrm{vi}}$. Officers ranged in age from 22 to 52 years, and had years of service in the police ranging from 2 to 28 years. All interviews were tape recorded and transcribed verbatim. The authors individually read and reread the transcripts and then separately developed analytic categories based on the data and the existing literature. These categories were then compared and discussed and categories subsequently refined, revised and developed as appropriate. Transcripts were coded using the qualitative data analysis package NVivo, and were analysed systematically using analytic induction (Frankland \& Bloor 1999).

In the interviews officers were asked to draw on their own experiences dealing with rape cases. In doing this, officers almost overwhelmingly referred to cases where the complainant was female and the perpetrator male. This is perhaps not surprising given that according to the legal definition of rape ${ }^{\text {vii }}$, this is an offence that may only be committed by a male and that the majority of rapes that are reported to the police are committed against women: the complainant was female in 389 of 411 rapes reported in $2007 / 8$, which is $94.6 \%$ of all cases in the force in question. This is reflected in the data presented below, and for this reason we use gendered language in discussing the data as this is in keeping with officers' accounts and responses. Additionally, the title SOLO has been retained by the Police force in this research, and as such the role of STO is referred to as the SOLO role for data presentation as this is the language used by the police officers involved in the research

\section{Findings}

The findings of the research show that the majority of police officers recognise the value of the SOLO role, and aim to perform it to the best of their ability, however there are a number of barriers and challenges for SOLOs.

\section{Dual Role as SOLO and Response Officer}

A significant issue for police officers in the research was the management of their dual roles as both SOLOs appointed to a particular rape or sexual offence case, and their ongoing responsibilities as a uniform response officer. This issue was raised in relation to the performance target culture under which officers were operating at the time of data collection. Concerns were expressed that performing the SOLO role detracted from performance in other aspects of the policing job and that this would not always be taken into account in any performance assessement. For example:

I mean a friend of mine works at 'Hillville', she got put on monthly reports, which means you have to go and have a chat about your performance, because you have to have $x$ amount of arrests, $\mathrm{x}$ number of stop searches, $\mathrm{x}$ number of intelligence forms put in, I don't even know what the indicators are now, actually, so the fact that they've used the whole shift isn't valued at all, and she'd spent I think the last 3 months, she'd done a lot of solo jobs, so well she's not out getting prisoners in. (female detective)

Well up until recently, it's just changed, but they all had individual performance targets, things that they had to do every month and record how many they had done of them and if they hadn't met their target then they'd be sort of taken in for an interview, questioned why, given action plans 'how you can improve your performance', but if you were a SOLO officer then that didn't feature on this spread sheet. So you could deal with so many sexual 
offences in the course of a month which might take up a significant period of time during which you are not able to do your normal tasks and gather all the other bits to tick all the boxes you are supposed to tick, there was no allowance made for that. But that has just ended, they have taken away that - individual targets. (male detective)

The significant time commitment involved in performing the SOLO role was also an issue raised by police officers. They highlighted how this impacted on the rest of their professional work in terms of targets, but they also indicated the effect this had on them in terms of hours worked, and their welfare. Some officers stated that the long hours worked had prompted them to request temporary removal from SOLO duties. For example:

You are always off late if it's a SOLO job - always. But no, you don't get any extra time to do your other work because you are a SOLO. (female detective)

... it was just getting a bit crazy because I didn't have the time, and going out in the car responding to day to day jobs, and so on and so forth, and being a response officer, to keep up to date with everything, so I actually asked for a period of time out to say l've spent, because inevitably rape investigations are very very long hours, very resource draining, it's very intensive. (female SOLO)

Officers also indicated that their experience was dependent upon the quality of, and relationship with, their immediate supervisor. Some officers indicated that supervisors were sympathetic to the fact they were performing additional SOLO responsibilities on top of their normal response policing role, however others had experiences of supervisors who were not sympathetic to their situation. As such, their experience of performing the role was, to some extent, dependent upon a good supervisor and a good relationship between them.

When you're dealing with a SOLO obviously you're not looking at your other jobs, and sometimes I know that sergeants do take into account that you've dealt with a SOLO job on maybe that day, where you haven't been able to do your enquiries, but at the same time that job needs to be, the original jobs that you are dealing with, would be reviewed every fourteen days. (male SOLO)

You are taken out two days in a row, that's two days in a row that you are not able to carry out any enquiries, the skipper is then on your back - 'look at your work load! You've got 10 jobs - you've not done anything!' (male SOLO)

\section{Officer Welfare}

It is evident from our data that these significant time commitments, and the balancing of two roles, impacts on levels of fatigue among officers. A number of officers drew attention to the extreme tiredness that affected them when they were required to work beyond the end of their scheduled shift in order to perform the SOLO role and support a victim of rape.

So the shift would start, I'd do my shift, an hour before I was due to book off a job would come in in 'Hillville' for instance, so l'd be deployed from 'Seatown' to 'Hillville', and I lived in 'Springtown' at the time, honestly I'd be so tired, there were times when I had to pull over driving back from work and have a doze in my car because to carry on driving would actually be really dangerous, and I just felt I just can't, I just couldn't cope with it. (male SOLO) 
I was being called an awful lot and I dealt with a huge vast amount and it got to the point where I was actually getting confused, thinking sorry which one are you, and who are you (female SOLO)

The research also found that officers' personal needs in relation to food, drink and breaks were not often met when they were performing the SOLO role and when they were operating outside the normal work environment and supervision structure.

I can remember being in the victim suite in 'Hillville' and I' $d$ been booted out the door at $7 \mathrm{o}$ clock in the morning, and it was 4 o clock in the afternoon and I'd still not had any lunch and I was starving, and I couldn't think straight because I was so hungry, and in the end I had to ring my sergeant and say is there any chance someone could just drop a sandwich off for me please, they went oh yeah we forgot about you, and it's like well how can I do my job properly if you're not looking after me because I need to eat, and you know my victim as well was starving, so you'd share your lunch round, saying do you want half a sandwich and it's just so bad. (female detective)

The extract above also indicates the role supervisors need to take in ensuring that SOLOs are appropriately supported and their welfare needs are met. Supervisors also have a role to play in ensuring that officers are not over-deployed in the SOLO role. This is particularly important given that previous research highlighted the likelihood of 'burn-out' for SOLO officers and that steps should be taken to avoid this (Sturman (2000), cited in Kelly, 2002). As one officer noted:

There was one officer that was doing a solo time and time and time again, and she's very committed, she's very professional, and my concern was you're getting an awful lot and you're being stuffed and I don't think this is right, and I spoke to her and said do you need time out, are you alright, have you got enough people looking after you, and she said do you know, you're the first person out of everybody that's ever sat down and asked me that, and I said well do you want to talk about it. (female SOLO)

\section{Management \& Supervision}

Previous research and reviews have drawn attention to poor supervisory arrangements in relation to the SOLO role (HMCPSI \& HMIC, 2007) and the findings from the research mirror these to some extent. For example, police officers commented on the fact that performing the SOLO role takes them out of the normal supervisory structure, and places them temporarily under CID officers. However this is not a formal supervisory shift, and leads to ambiguity about who has primary responsibility for the officer when they are performing SOLO duties and that ongoing communication is not always good leading to a sense of isolation and lack of support for officers.

In my experience of solo jobs I've had very little support from my sergeants, and once you get assigned to it that's it, it feels like they push you to one side, you deal with it, you're on your own, you volunteered to be a solo, get out there and deal with it, whereas when you come back to your normal work you do get a lot more support and you feel like a part of the team and they will give you guidance on things. (male SOLO)

Historically, uniform supervision won't monitor it, it's oh you're a solo, and to them it's a burden because you're taking my staff away and I need staff for this, and oh here we go again type scenario, and it depends on I think the individual manager. (female SOLO) 
In contrast, other officers drew attention to aspects of good practice in relation to management and supervision where supervising Sergeants were cognisant of the needs and additional burdens impacting on the SOLO officer. For example:

Some of the Sergeants are really good, they see you come in and they know what you are still doing here because they think 'your team was off hours ago, you must have had a SOLO job, l'll get someone from my team to help out', and it's just things like sealing up the clothing bags has to be done a certain way and they take a good ten minutes, little things like that, just a bit of understanding that you've been here for hours. (female SOLO)

\section{Lack of Support\& Poor Understanding of Role Importance}

Many police officers reported feeling unsupported in performing the role of SOLO and felt that they were very much expected to 'go it alone' with minimal guidance from investigative officers.

I just felt unsupported really when I was at the jobs. Literally you were just left to get on with it, different CID officers, some were better than others at ringing you up and seeing if you needed anything or helping you organise things, because there's a lot of things that need to come together to make the initial investigation work, for instance you know scene guards need to be arranged, the FME needs to be arranged, the victim suite needs to be prepped up and the keys delivered, and all sorts of things, it takes time and I just didn't feel very supported with all that organisation, because that was pretty much left up to me to make sure it was all going to go off without a hitch. (male SOLO)

The respondents were also aware that the role of SOLO was not always valued and other aspects of policing were given precedence in the supervisory structure. They commented that this made it more difficult to do the job, and was experienced by officers as an additional pressure on them and as a potential source of conflict. Officers indicated that they did not always feel supported by their immediate supervisors in their decision to be an active SOLO. The following interview extracts illustrate this point:

Try and put them first when you've got other duties that your Sergeant has said 'look I need you to investigate this burglary', you sort of say 'yeah I know that's important but this has really effected someone's life, this has got to come first', it's hard to get understanding from your own Sergeants because they normally have nothing to do with the investigation, it's all $\mathrm{CID}$, you sort of work under them, but at the time your sergeant wants you to work exactly the same as everyone else, it's really difficult sometimes when you have to say 'look, yes you're my supervisor and I have to do what you say, but I'm afraid I can't do this', so it can be quite tough. (female SOLO)

Police officers in the research suggested that supervisors needed more education in terms of the SOLO role, its importance and management. This is consistent with the HMCPSI and HMIC (2007) report that stated the SOLO role is not widely understood at supervisory level. For example, one officer noted:

Because the uniform supervisors, it's like a member of their staff is sort of plucked away and taken out of the game for a long time, half a shift, a whole shift and probably some of the following shift, so no sort of perceivable gain going to them. So it's a matter for the organisation to mainly educate uniformed supervisors better to value that role. (male detective) 


\section{Ongoing Communication with Victims}

Since 2006, The Code of Practice for Victims of Crime requires the police to notify victims if or when there is to be no investigation in to the reported crime, and ensure victims can access services and support. They are also required to notify victims of case progress and if no one is charged in serious offence cases. As many rape cases can involve lengthy investigations and protracted trial processes, the ongoing time commitment that the SOLO officer needs to commit to liaise with the victim can be quite considerable.

But officers also indicated that significant ongoing contact with the victim does not always, or often, happen in practice. This is despite that fact the description of the SOLO role includes this aspect (HMCPSI \& HMIC, 2007). As officers commented:

[SOLOs are] supposed to be with them throughout, aren't they, quite often, throughout the whole process, court, everything, to stay in contact and stuff, I don't think in practice that happens. (female detective)

I don't think it works as it was supposed to work, in that they were supposed to be the point of contact with the victim all the way through, because I still think they just still do that first part and then it's left to the OIC after that. (female detective)

It was clear from officers' comments that there was some ambiguity about with whom primary responsibility for ongoing contact with the victim lay. In some case SOLOs believed this was their primary responsibility and an integral part of the role, however a number of respondents indicated that in practice ongoing communication with the victim was often taken over by the investigating officer in CID, or the 'Officer in Charge' (OIC). This, to some extent, was down to the particular preference of the Officer in Charge of the case:

A lot of the time the officers on the case didn't use you as the point of contact, and would just contact them themselves, which I think was part of being a solo was to be the contact point, to save the officer on the case having to always be in contact, you know to take that off their load, but I think, being an officer on the case now, I quite like to contact them myself because I just prefer it that way rather than having to go through someone else, it's just easier. (male detective)

Our role is to basically deal with the victim from the very early stages so that she or he has one person to liaise with through the whole - it should be the whole case until court - but it doesn't really work like that unfortunately, mainly 'cause a lot of them don't get to court, mainly 'cause CID take them on after us, after we have dealt with them. (female SOLO)

Police officers also indicated that ongoing communication with the victim could not always be done by the SOLO due to their other time commitments and their dual role as SOLO and response officer:

Yeh that's ideally who it is so that you're that person's contact for that investigation, but it's very difficult for that to actually work when you're on MPT, you're in uniform, you're answering all the 999 calls, you're on $24 / 7$ sort of thing, it's very difficult to actually do that so actually the investigator took on your role and would become the contact for the aggrieved because it was just too difficult, because when they needed them updated, you were off, you're on call, you're on holiday, you're on nights, and you can't call someone at 
one o'clock in the morning, and it was very difficult to complete that side of the solo role. (female SOLO)

\section{Monitoring and Feedback}

The data shows that officers performing the SOLO role did not often receive adequate monitoring or feedback about cases. Officers told us that they often did not know the outcome or progress of the case beyond their initial involvement and this lack of feedback contributed to them feeling less valued in their role as SOLO. This again is consistent with the findings of the HMCPSI \& HMIC (2007) report that found monitoring of performance was rare and feedback to SOLOs from the OIC did not often occur. The police officers in our sample indicated:

I have only once been contacted by an officer investigating to say what's happened, what the outcome was, nobody bothers getting back to the SOLO to let them know, which I have to say, I feel a little aggrieved about, I mean if I want to find out, I have to then go and do a lot of research to find out what the crime number was, and who was investigating it and then what's happened, which, I have a workload as well, I don't really have the extra time to be able to do that, but it's a great shame. (female SOLO)

Yes I'd like to be kept in the loop, just because I invest a lot of hard work initially, and it would just be nice to know the outcome and I think that's understandable. I mean I do get the impression that they're very busy, I don't really want to put any more pressure on them. (male SOLO)

\section{Role Ambiguity: Support or Investigation?}

Our research findings highlight that there is some ambiguity surrounding the role, purpose and remit of the SOLO. This ambiguity primarily centres round whether the SOLO role is one of support or investigation. Our data shows that some officers conceptualise the SOLO as primarily a support role, and one that is confined to eliciting immediate information from the victim, whereas other police officers consider the SOLO an active member of the investigative team in terms of trying to establish the veracity of the account from the victim. For example:

They're trained to do it in a particular way, which is open and supportive, they're not trained to be inquisitors, or investigators, as such ... (male detective)

The solo role at the moment is a role where we are saying just get an account, just listen to what the victim says, don't challenge anything, listen to what they say, take it all in and write it all down ... (senior female detective)

A solo officer from my definition in a very short phrase way of putting it which is not belittling the role at all, is you're there to buddy up with the victim of that crime, you're there pure and simply to do as a supporting role, whatever they may want you to do for them. (female SOLO)

In contrast:

You are an investigator as well, and there's no point in me wasting my time, CID wasting their time if the allegation is complete rubbish, you do get some, I can't remember anything off the top of my head but if I looked at my database I would, but we just, you just know 
straight away it's just complete and utter rubbish, and it's just unbelievable what they're saying, and it just quite feasibly could not have happened. (female SOLO)

However, police officers reported that performing the role of SOLO required them to suspend their normal policing instincts and to some extent disregard their initial training as police officers where they are encouraged to doubt what people tell them. Police officers therefore found the SOLO role challenging because they had to suspend their usual inquisitive approach.

You're trained as a Solo that your victim's story is your victim's story, it needs investigating, you don't doubt them, you kind of believe them. As police officers you're trained that you doubt everything you ever hear and you investigate it to the ends of the earth to try and find some evidence, so it's really quite hard because your first training is as a police officer and everybody becomes very doubting, very cynical, very quickly in the police (female detective)

\section{Concern About Fair Procedures and Good Treatment}

Our data shows quite clearly that officers performing the SOLO role felt strongly about the importance of their role in terms of a positive experience for the victim, and treating the victim with due fairness and respect. This in part surrounded the perspective that victims of rape who report to the police deserve to have their story heard and believed, and the belief that SOLOs have the opportunity to make a potentially very unpleasant experience more tolerable for the victim. For example:

I think as a solo it's very wrong to go in with any thoughts of oh yeh you're just trying this on and it hasn't happened and you're just making a scene you're trying to get attention seeking or anything like that, you have to go in and treat every single job as a real pucker genuine rape ... (female SOLO)

We had one guy [FME] come up and he was quite demonstrably irritated because he had to come from 'Hillville' and he, I explained to him what had happened and he wanted to know whether I thought that she was credible.[..] I said well I don't care, this is not an assessment that I make at this stage [..] so I said my job is not to care about that, and frankly doctor it's not your job to care about it either. (male SOLO)

However, as has already been highlighted above, the constraints on SOLOs mean that whilst police officers would often want to treat victims with respect, compassion and fairness, practical constraints mean officers are not always able to see this commitment through and must therefore maintain appropriate boundaries. As such, intention does not always equate to practice. For example:

I've got a lot of compassion for the victims and I do care about them, that's why I do the job, but by the same token, I can't let them get too embroiled with just one police officer, they need to get a rapport with the actual officer on the case, the DC who's going to be dealing with them, and also I can't, I'd only let them down because I've got too many other demands on my time, quite apart from my personal life, because people do end up getting phone calls at home and all sorts of things, so the exit strategy for a solo is phenomenally important, and I would tend to make it obvious from the start that l've got an important job but a limited job, and when I've finished, we'll be going our separate ways. (male SOLO)

\section{Discussion}


The findings of the research suggest that many officers are committed to performing the STO role well, and recognise the importance for the victim of receiving a good police response to reported rape. However the findings also raise some concerns, particularly in relation to deployment, management and supervision, and the impact of poor management on individual officer welfare.

As noted earlier, the STO role had previously been done, on a lesser remit, by officers known as 'chaperones'. In her research with the Metropolitan Police Service in the 1990s, Temkin found that chaperones 'emerge as secondary victims in the rape process. Trained to be the standard bearers of the new regime, they find that in practice they are deprived of the time and resources to provide a proper service' (1999: 28). These findings were to some extent reiterated by the HMCPSI and HMIP (2007) joint review that highlighted ongoing problems in relation to deployment and supervision. This more recent data concurs with these findings and shows that the concerns raised the report remain largely unaltered. The findings that STOs were not often adequately supervised whilst performing the STO role and outside the usual uniform supervision structure, that line-management responsibility was not often clear, and that the importance of the STO role was not widely understood at supervisory level directly mirror the findings of the HMCPSI and HMIC (2007) report. This suggests there have been little or no interventions since the report's publication, or what interventions there have been have not been successful and alternative approaches will be needed.

It is also likely that police culture plays a significant role in the extent to which both police officers, and supervisors, prioritise the role of the STO. The primary role of the police has always been closely associated with the enforcement of law (Manning, 1977; Bayley and Shearing, 1996) and the informal structure of norms and values that operate within the more rigid hierarchy of the police organisation (Holdaway, 1983) have reinforced this predominately masculine culture. Fielding (1994) argues that the police subculture represents almost pure hegemonic masculinity and stresses aggression, competition and a heterosexist atmosphere. Police officers are thus expected to show physical and emotional strength, fight crime, and protect the public from crime and natural disasters (Brown and Campbell, 1984, cited in Page, 2007); this is often what is considered 'real' police work. 'Rape work' does not fit very well within this framework, and it has tended to be considered too 'feminine'. Similar arguments are found in relation to domestic violence; that it is unlikely to be prioritised by officers because it has often been considered inconclusive, low status work that detracts police officers from their pursuit of 'real' police work (Edwards, 1989). It is clear that some aspects of the traditional culture are still in operation, not least because as the data shows STO deployment/work load does not show in performance targets or assessments and is often not valued or fully understood. It is the case that organisations and institutions count and measure those aspects they attach most value to, and the data from officers clearly shows a lack of understanding on the part of immediate supervisors in particular, who put pressure on STOs to prioritise the 'real' police work of crimes such as burglary and their related outcomes and targets.

Operating in this police culture, it is clear from the data that police officers operating as STOs experience a degree of role conflict which is evident on two levels: firstly the dual role of operating as an STO whilst still retaining responsibilities as a response officer with their accompanying targets; and secondly between believing the victim and providing a sensitive response to reported rape and their initial training to disbelieve and be suspicious. To some extent both of these conflicts can be summarised as the conflict between the investigation of crime and the care and welfare of victims, and this directly relates to the discussion of police culture above. It is also the case that similar role conflicts have been evident in research on other aspects of post assault intervention, for example forensic medical examiners and nurses (Du Mont and Parnis, 2000, 2001; McMillan, 2010; Parnis and Du Mont, 2002, 2006; Mulla, 2011; Rees, 2010; Savage et al, 1997). 
The police officers involved in the research recognised the importance of the STO role, despite the fact this was not always shared by their immediate supervisors. The initial police response in rape cases is extremely important and the STO is an integral part of this. We know that whilst victim experience is improving, many do not have a positive experience and Myhill \& Allen's (2002) analysis of British Crime Survey data found $22 \%$ were dissatisfied with the police handling of their case. Research also tells us that '...several mentioned that, in the event of a similar occurrence, they would not report again.' (Temkin, 2002: 278). It is precisely this sort of evidence that prompted the introduction of the the STO role in the first instance, and it is clear that the role can be performed well. It is also vital that it is performed well given the significant contribution victim withdrawal makes to the attrition problem. It is also likely that good initial contact with a complainant in a rape case increases the likelihood of full participation in the process - that is moving beyond providing a 'first account' of the incident, to participating in a full statement and forensic medial examination. Both these aspects are vital if cases are to be successfully investigated and prosecuted and if the necessary information is not elicited from the victim when they first encounter the police, this can have a significant impact on scene identification, forensic retrieval opportunities and suspect identification (Lonsway, Welch \& Fitzgerald, 2001).

It is particularly reassuring that the data shows that police officers performing the STO role understand the importance of making sure victims feel their story is believed. Previous research has highlighted the negative experiences victims who report rape have had and these often surround the perception that their story is not believed, nor taken seriously, by the police. For example, Temkin's research in Sussex and London $(1997 ; 1999)$ found that disbelieving attitudes of the police, insensitive handling of reports, the uncaring and unsupportive attitudes of officers and an overconcern about convictions rather than victim care was particularly difficult for complainants. Similarly, McMillan and Thomas (2009) reported that victims often felt they had to convince police officers of the veracity of their account. The data suggests the role of STO is taken seriously by the majority of officers who perform it, and that believing the victims they deal with is an important part of the role. Officers did, however, note that this can be challenging for them as it does, to some extent, run counter to their initial police training of being inherently suspicious and questioning. It is difficult to know how this particular dilemma might be challenged given this inherent scepticism is encouraged from the first day of police training, however previous research does indicate that police officers (and the general public) are likely to believe that rape is falsely reported more than other crimes (Blair, 1985; McMillan, 2010; Temkin, 1997). As such, one recommendation is more in-depth education for police officers about the likely 'true' level of false rape reporting and the importance for the victim of 'honouring the experience' (Stern, 2010).

Research has already drawn attention to the importance of ongoing communication for victims involved in the criminal justice process, and the Code of Practice for Victims of Crime (2006) compels the police to communicate adequately with victims of crime, particularly serious crime, of which rape is. Ongoing communication and liaison is a key element of the STO role however this research indicates that in practice this is not often performed by the STO themselves, but is often taken over by the investigating officer in a case. Whilst this is not necessarily problematic in itself, as communication by the investigating officer may be quite adequate, it does however lead to a lack of clarity in terms of roles and responsibilities. Further, it also leads to a lack of consistent treatment for the victim of rape and does not allow the STO to support victims through the process in its entirety. It is particularly important that this aspect of the police response to rape is approached properly given that research has shown that those who report rape often have reasonably positive attitudes towards the police in general, but much less positive attitudes in relation to the amount of ongoing information and communication (Frazier \& Haney, 1996). 
Additionally, the findings also indicate the particularly time-consuming nature of ongoing communication with the victim in cases of rape, and that this in part explains why STOs are not practically able to facilitate this. But for any police officer (STO or investigative officer) it is a considerable time commitment. It is important that victims receive a good response from the police and procedural justice and fairness could equate to consistency of treatment and at the moment this data shows that victims are not given a consistent response. Some STOs go above and beyond the remit of the role, whereas others do the minimum, or are prevented from giving the best service possible due to role and management constraints. Given the time and role constraints that police officers performing the STO role currently operate under, the importance of ongoing communication with the victim, and the potential burden fulfilling the role to the full may place on police officers, the findings provide support for the wider-spread introduction of Independent Sexual Violence Advisors (ISVAs) or similar advocacy roles, who could support some aspects of the work currently done by STOs. ISVAs perform the role of ongoing support for the victim throughout the criminal justice process, from report through to trial, or however far the case progresses through the justice process. Their role is to support the victim, liaise with other support agencies, act as an advocate with other criminal justice agencies, and provide an ongoing regular point of contact for the victim. Importantly, the ISVA is independent of the criminal justice agencies the victim has to deal with (Stern, 2010).

The use of ISVAs potentially brings benefits for the victim and the police. The ISVA has the potential to help the police by supporting the victim, thus keeping them on board and more likely to participate in the criminal justice process, as well as potentially freeing police STO resources for other tasks. The ISVA role would not preclude the existence of the STO role as first responder and provider of FME support and so on, but would allow the role of STO to have tighter boundaries. The ISVA is a dedicated role, and would not have the pressure of other demands in the way STOs have dual roles as response police officers. As such, the research findings concur with those of The Stern Review that states that the 'police should not have to work on their own to deal with rape complainants' (2010:118) and recommends '.... that Independent Sexual Violence Advisors be seen as an intrinsic part of the way rape complainants are dealt with, as the service that enables the rest to operate effectively and a crucial part of the way the state fulfils its obligations to victims of violence.' (2010: 106).

To fulfil this obligation in Scotland, Police Scotland have very recently introduced a pilot project with Rape Crisis Scotland to provide victim advocacy and support to those reporting rape to the police. The pilot project, funded by the Scottish Government and commencing in 2014, will see advocacy workers offered to victims who report rape to the police. Rape Crisis, an organisation well versed in victims' potential needs (McMillan, 2007) will both employ and manage the advocacy workers therefore they remain distinct from the state institutions that comprise the justice process. Their remit will include support with criminal justice and legal aspects as well as welfare needs beyond the justice process. This is similar to ISVAs in England and Wales where ISVAs are resourced by Home Office funds provided to both voluntary and community organisations such as Rape Crisis, and to Sexual Assault Referral Centres (SARCs).

It is however the case that ISVAs and other approaches to advocacy provision such as those being piloted in Scotland, should not be instead of the STO role, but rather as well as. Nor is it the case that ISVAs should be the sole bearers of responsibility for the welfare of the victim; the provision of advocacy does not somehow devolve the police service of its responsibility. Corrigan (2013) provides supporting evidence from her research with 150 rape care advocates in the US, finding that rape care advocates were able to provide a complementary service to that of the police, resulting in an overall better experience for the victim. Corrigan (2013) also found that independent victim advocacy, provided by community organisations such as rape crisis centres, was more effective in 
complementing the work of the police, whereas law-enforcement or systems-based advocacy was less likely to offer victims the support they needed in the criminal justice process as it was less able to challenge the systems themselves. In terms of victim welfare and support any use of ISVAs needs to happen in concert with STOs who understand their role not only as a collector of evidence or supporter of an investigation, but as a police officer primarily charged with supporting the welfare and needs of the victim in what can be a very difficult process. It also is of course the case in times of increasing austerity and reduction in funding for public services that the provision of ISVAs in some areas of England and Wales is under threat. For some areas, then, the ability to continue to provide this service for victims may be in question. However it is, in the current climate of austerity Britain, a matter of setting appropriate political priorities and making a commitment to good justice outcomes for victims of sexual crime, which given the poor victim experience outlined earlier in this paper, remains a pressing matter. Other jurisdictions in the UK, namely Scotland, have recently made a clear commitment to giving the welfare and support of rape victims high priority. Police Scotland's recent successful application to secure Scottish Government funding for a pilot advocacy project to be run and managed by Rape Crisis Scotland (Police Scotland, 2013) suggests that where political will exists, funding can be sought.

It is possible that procedural justice could be achieved for victims of rape and sexual offences if the STO role and the ISVA role complimented one another to provide the best possible support and fair treatment for victims throughout the process. It may also be that if successfully achieved, a greater number of victims may participate in the criminal justice process, and a greater number may participate longer, and this may in turn impact on the conviction rate for rape. In any case, successful provision of the STO and ISVA role is a central element of procedural justice for victims, and a successful justice response to sexual violence needs to be assessed in a number of ways including addressing the conviction rate, but also critically reflecting on victim experience and procedural justice. As The Stern Review highlights 'Support and care for victims should be a higher priority.'(2010: 11).

It is clear that as the HMCPSI \& HMIC (2007) report highlighted, the introduction of specialist provision such as STOs, sexual assault referral centres (SARCs) and CPS rape co-ordinators has led to significant improvements in the criminal justice response to rape. However this research concurs with the assertion in the report that "intention" is not yet fully effective in practice on the ground, and several fundamental difficulties persist that are constraining the potential for more significant and sustained improvement'. (p21).

\section{References}

Adler, Z. (1991) Picking up the Pieces, Police Review, $31^{\text {st }}$ May, pp. 1114-5

Bayley, D. H. and Shearing, C.D (1996) Law and Society Review 30(3): 585-606

Blair, I. (1985) Investigating Rape: A New Approach for the Police, London: Croom Helm

Chambers, G. and Millar, A. (1983), Investigating Sexual Assault, Edinburgh: Scottish Office Central Research Unit

Corrigan, R. (2013) Up Against A Wall: Rape Reform and the Failure of Success, New York: New York University Press

Curtis, S. (1995) Gender Friendly, Police Review, 103 (5318), 19 $9^{\text {th }}$ May, pp. 28-9 
Du Mont, J. and Parnis, D. (2000) Sexual Assault and Legal Resolution: Querying the Medical Collection of Forensic Evidence, Medicine and Law 19: 779-92

Du Mont, J. and Parnis, D. (2001) Constructing Bodily Evidence Through Sexual Assault Evidence Kits, Griffith Law Review 10: 63-76

Edwards, S. (1989) Policing Domestic Violence: Women, the Law and the State, London: Sage

Erez, E. \& Bienlowska, E. (1993) Victim participation in sentencing and satisfaction with justice, Justice Quarterly, Vol, 9, pp. 393-419

Fileding, N. (1994) Cop Canteen Culture, in Newburn, T.A. and Stanko, E.A. Just boys doing business? Men, Masculinities and Crime, London: Routledge

Frazier, P.A. \& Haney, B. (1996) Sexual Assault Cases in the Legal System: Police, Prosecutor, and Victim Perspectives, Law and Human Behaviour, Vol. 20, No.6, pp. 607-28

Gregory, J. \& Lees, S. (1999) Policing Sexual Assault, London: Routledge

Harrison, R. (1998) Treating Trauma, Police Review, $22^{\text {nd }}$ May, pp.24-5

Hepworth, S. (2003) The Right Words, Police Review, $5^{\text {th }}$ December, pp.26-7

Holdaway, S. (1983) Inside the British Police Force: A Force at Work, Oxford: Basil Blackwell

Home Office (2006) The Code of Practice for Victims of Crime, London: Home Office

HM Crown Prosecution Service Inspectorate (HMCPSI) (2002) A Report on the Joint Inspection into the Investigation and Prosecution of Cases Involving Allegations of Rape, London, HMCPSI

HM Crown Prosecution Service Inspectorate (HMCPSI) \& HM Inspectorate of Constabulary (HMIC) (2007) Without Consent: A Report on the Joint Review of the Investigation and Prosecution of Rape Offences, London: HMIC

Jamel, J., Bull, R. \& Sheridan, L. (2008) An investigation of the specialist police service provided to male rape survivors, International Journal of Police Science and Management, Vol. 10, No.4, pp. 486508

Jordan, J. (2001) Worlds Apart? Women, Rape, and the Police Reporting Process, British Journal of Criminology, Vol. 41, pp. 679-706

Kelly, L. (2002) A Research Review on the Reporting, Investigation and Prosecution of Rape Cases, London: HMCPSI

Kelly, L., Lovett, J. \& Regan, L. (2005) A Gap or a Chasm?: Attrition in Reported Rape Cases, Home Office Research Study 293, London: Home Office

Lea, S.J., Lanvers, U. \& Shaw, S. (2003) Attrition in Rape Cases. Developing a Profile and Identifying Relevant Factors, British Journal of Criminology, Vol. 43, pp. 583-99

Lind, E.A. \& Tyler, T.R. (1988) The Social Psychology of Procedural Justice, New York: Plenum Press 
Lees, S. \& Gregory, J. (1993) Rape and Sexual Assault: A Study of Attrition, London: Islington Council

Lonsway, K.A.., Welch, S. \& Fitzgerald, L.F. (2001) Police Training in Sexual Assault Response: Process, Outcomes, and Elements of Change, Criminal Justice and Behavior, Vol. 28, pp. 695-730

Maier, SL (2008) 'I have heard Horrible Stories...': Rape Victim Advocates' Perceptions of the Revictimization of Rape Victims by the Police and Medical System, Violence Against Women, Vol. 14, No. 7, pp. $786-808$

Manning, P. (1977) Police Work: The Social Organisation of Policing, Cambridge: MIT Press

McMillan, L. (2007) Feminists Organising Against Gendered Violence, London: Palgrave

McMillan, L. (2010) Understanding Attrition in Rape Cases ESRC End of Award Report RES-061-230138-A, Swindon: ESRC

McMillan, L. \& Thomas, M. (2009) Police Interviews of Rape Victims: Tensions and Contradictions, in Horvath, M. \& Brown, J. Rape: Challenging Contemporary Thinking, Willan Publishing

Mulla, S. (2011) Facing Victims: Forensics, Visual Technologies, and Sexual Assault Examination, Medical Anthropology, 30(3)L 271-294

Myhill \& Allen, (2002) Rape and Sexual Assault of Women: Findings from the British Crime Survey, London: Home Office

Morgan, D. (2003) Family Matters, Police Review, $12^{\text {th }}$ December, pp. 20-1

Nicholls, M. (1998) Softly, Softly, Police Review, $16^{\text {th }}$ January, pp.28-9

Parnis, D. and Du Mont, J. (2002) Examining the Standardised Application of Rape Kits: An

Exploratory Study of Post-sexual Assault Professional Practices, Health Care for Women International 23: $946-53$

Page, A.D. (2007) Behind the Blue Line: Investigating Police Officers' Attitudes Toward Rape, Journal of Police and Criminal Psychology 22(1): 22-32

Paternoster, R., Brame, R., bachman, R. \& Sherman, L.W. (1997) Do Fair Procedures Matter?: The Effect of Procedural Justice on Spouse Assault, Law and Society Review, Vol. 31, No. 1, pp. 163-204

Police Scotland (2013) Service Level Agreement Between Police Scotland and Rape Crisis Scotland: Pilot Advocacy Support Service, Glasgow: Police Scotland

Rees, G. (2010) 'It is not for me to say whether consent was given or not': Forensic Medical Examiners' Construction of 'Neutral Reports' in Rape Cases, Social and Legal Studies, 19(3): 371-386

Resick, P.A. (1987) Psychological effects of victimisation: Implications for the criminal justice system, Crime and Delinquency, Vol. 33, pp. 468-78

Robinson, A. (2009) Independent Sexual Violence Advisors: A Process Evaluation, London: Home Office 
Savage, S.P., Moon, G., Kelly, K. and Bradshaw, Y. (1997) Divided Loyalties?: The Police Surgeon and Criminal Justice, Policing and Society 7: 79-98

Seneviratne, M. (2004) Policing the Police in the United Kingdom, Policing and Society, Vol. 14, No. 4, pp.329-47

Shapland, J., Willmore, J. \& Duff, P. (1985) Victims in the Criminal Justice System, Aldershot: Gower Publishing

Stern, V. (2010) The Stern Review: A Report by Baroness Stern CBE of an Independent Review into How Rape Complaints are Handled by Public Authorities in England and Wales, London: Home Office

Symonds, M. (1980) The second Injury to Victims in Violent Crime, Evaluation and Change, Special Issue

Temkin, J. (1997) Plus Ca Change: Reporting Rape in the 90s, British Journal of Criminology Vol.37 No. 4 , pp. $507-28$

Temkin, J. (1999) Reporting Rape in London: A Qualitative Study, The Howard Journal of Criminal Justice, Vol. 38, pp. 17-41

Temkin, J. (2002) Rape and the Legal Process, $2^{\text {nd }}$ Edition, Oxford: Oxford University Press

Thibaut, J. \& Walker, L. (1975) Procedural Justice: A Psychological Analysis, New York: Wiley

Tyler, T.R. (1990) Why People Obey the Law, New Have: Yale University Press

Wemmers, J., van der Leeden, R. \& Steensma, H. (1995) What is Procedural Justice: Criteria Used by Dutch Victims to Assess the Fairness of the Criminal Justice Procedures, Social Justice Research, Vol.8, No.4, pp. 329-50

\footnotetext{
' In April 2006 Statutory Charging was implemented nationwide across England and Wales. This means the Crown Prosecution Service, rather than the police, make the decision whether to charge in rape cases.

ii ii At the time of the research STOs in the force areas, referred to as SOLOs, did not conduct the victim interview. This was done by CID officers. This practice is currently changing and all SOLO officers will be trained to the appropriate level of interview training in order be an integral part of the victim interview in the future. The practice of STOs not interviewing the victim is unusual (see HMCPSI \& HMIC, 2007).

iii Although rape investigations follow national guidelines, strategies and policies may vary across different forces. At the time of data collection the Police Force Strategy dictated that upon the report of a rape or serious sexual offence, a specially trained Sexual Offence Liaison Officer (SOLO) would be deployed and this officer would be responsible for taking a first account, accompanying the complainant to a 'victim suite' and assisting in the forensic medical examination and liaising with the detective in charge of the case (OIC).

${ }^{\text {iv }}$ More SOLO officers were contacted that investigating officers due to the lower response rate from this group.

${ }^{v}$ For the purposes of protecting officer anonymity, for use of quotations from interviews 'senior officers' are defined as the rank of Detective Sergeant and above.

${ }^{v i}$ Where detectives had previously been SOLOs they were interviewed primarily about their current role.

vii According to the Sexual Offences Act 2003, rape is the penetration by the penis of somebody's vagina, mouth or anus, without their consent.
} 